\title{
Effect of Rosmarinic and Caffeic Acids on Inflammatory and Nociception Process in Rats
}

\author{
Giovana Duzzo Gamaro, ${ }^{1}$ Edna Suyenaga, ${ }^{2}$ Milene Borsoi, ${ }^{3}$ Joice Lermen, ${ }^{2}$ \\ Patrícia Pereira, ${ }^{4}$ and Patrícia Ardenghi ${ }^{1,5}$ \\ ${ }^{1}$ Departamento de Bioquímica, Universidade Federal de Pelotas, Campus Capão do Leão S/N Caixa Postal 354, \\ 96010-900 Pelotas, RS, Brazil \\ ${ }^{2}$ Instituto de Ciências da Saúde, Universidade Feevale, RS 239, 2755, 93352-000 Novo Hamburgo, RS, Brazil \\ ${ }^{3}$ Instituto de Ciências Básicas da Saúde, Universidade Federal do Rio Grande do Sul, Rua Sarmento Leite, 500, 107, \\ 90046-900 Porto Alegre, RS, Brazil \\ ${ }^{4}$ Universidade Luterana do Brasil, Curso de Farmácia, Rua Miguel Tostes 101, 92420-280 Canoas, RS, Brazil \\ ${ }^{5}$ Fundação Estadual de Produção e Pesquisa em Saúde/Centro de Desenvolvimento Científico e Tecnológico, Avenue Ipiranga, 5400, \\ 90610-000 Porto Alegre, RS, Brazil
}

Correspondence should be addressed to Giovana Duzzo Gamaro, giovanagamaro@hotmail.com

Received 12 January 2011; Accepted 10 February 2011

Academic Editor: S. R. Chen

Copyright (c) 2011 Giovana Duzzo Gamaro et al. This is an open access article distributed under the Creative Commons Attribution License, which permits unrestricted use, distribution, and reproduction in any medium, provided the original work is properly cited.

\begin{abstract}
Rosmarinic acid is commonly found in species of the Boraginaceae and the subfamily Nepetoideae (Lamiaceae). It has a number of interesting biological activities, for example, antiviral, antibacterial, anti-inflammatory, and antioxidant. The aim of the present study was to investigate the effect of the i.p. administration of caffeic and rosmarinic acid ( 5 and $10 \mathrm{mg} / \mathrm{kg}$ ) on anti-inflammatory and nociceptive response using carrageenan-induced pleurisy model and tail-flick assay in rats. The analysis of cells in the pleural exudates revealed a reduction of $66 \%$ of the number of leukocytes that migrated to the pleural cavity in the animals treated with $5 \mathrm{mg} / \mathrm{kg}$ caffeic acid, and of $92.9 \%$ for the animals treated with $10 \mathrm{mg} / \mathrm{kg}$ in comparison with the control group. These exudates showed a balanced distribution of polymorphonuclear (PMN) and mononuclear (MN) cells, differently from the control group, in which PMN cells were predominant. The analysis to tail-flick latency was increased in the group treated with $10 \mathrm{mg} / \mathrm{kg}$ caffeic acid characterizing a nociceptive response. While there was no difference between control group and animals treated with rosmarinic.
\end{abstract}

\section{Introduction}

Inflammation or phlogosis is a pathophysiological response of mammalian tissues to a variety of hostile agents including infectious organisms, toxic chemical substances, physical injury, or tumor growth leading to local accumulation of plasmic fluid and blood cells [1].

Although inflammation is a defense mechanism, the complex events and mediators involved in the inflammatory reaction can induce, maintain, and aggravate many disorders. This process is invariably characterized by the production of prostaglandins, leukotrienes, histamine, bradykinin, platelet-activating factor (PAF), and by the release of chemicals from tissues and migrating cells $[2,3]$. It is well known that the central feature of inflammatory activity is the activation of phagocytic cells that synthesize and release large amounts of reactive species, causing cell and tissue injury, often directly by oxidative degradation of essential cellular components [4].

Following tissue injury and inflammation, nociceptors are sensitized, causing previously mild or ineffective stimulation becomes painful [5]. In acute pain, nociceptive transmission comprises a network of neuronal arrangement distributed between peripheral, spinal, and supraspinal levels. This occurs through the action of neurotransmitters, neuromodulators, and intracellular messengers $[6,7]$.

Plants were historically the main source for obtaining therapeutic agents. Natural selection and competition 
among species led to the synthesis of secondary metabolites, and many are used as drugs with marked biological activities [8].

Rosmarinic acid is an ester of caffeic acid and 3,4dihydroxyphenyllactic acid. It is commonly found in Boraginaceae species and in the Nepetoideae subfamily of the Lamiaceae. It is also found in species of other higher plant families, and in some fern and hornwort species [9]. Rosmarinic acid has a number of interesting biological activities, for example, adstringent, antioxidative, antimutagen, antibacterial, and antiviral effects [10-16].

The anti-inflammatory properties of rosmarinic acid are thought to be based on the inhibition of lipoxygenase and cyclooxygenases, and on the interference of rosmarinic acid with the complement cascade $[9,17-19]$ and the inhibition of expression of inflammatory cytokines [20]. Caffeic acid also inhibits 5-lipoxygenase (5-LOX) and protein kinase C (PKC) activity [21,22] besides antioxidant activity [23-26].

Therefore, the aim of this study was to investigate and compare the effects of rosmarinic and caffeic acids in vivo on inflammatory and nociceptive processes using carrageenaninduced pleurisy model and tail-flick assay in rats.

\section{Materials and Methods}

2.1. Animals. Male Wistar rats (12-week-old, weighing 200$300 \mathrm{~g}$ ) from the animal unit of Universidade Feevale were used in this study. All animals were housed at $25 \pm 1^{\circ} \mathrm{C}$ with 12 hours light, 12 hours dark cycle and supplied with standard rat chow and water freely available. Animals were handled and cared according to NIH Guide for the Care and Use of Laboratory Animals and the Brazilian Society for Neuroscience and Behavior (SBNeC) recommendations for animal care. This study was submitted to Ethical Committee of Feevale and received approval by code no. 2.08.03.07.673.

2.2. Drugs and Pharmacological Procedure. Rosmarinic acid and caffeic acid were purchased from Sigma Chemicals (St. Louis, Mo., USA). Thirty minutes prior to procedures, animals were pretreated. For pleurisy model, rats were divided in five groups ( $n=7$ animals/group). Caffeic acid (5 and $10 \mathrm{mg} / \mathrm{kg}$ ) and rosmarinic acid (5 and $10 \mathrm{mg} / \mathrm{kg}$ ) were administered intraperitoneally, using saline as vehicle. The control group were received saline $(2 \mathrm{~mL} / \mathrm{kg})$ by the same route. For tail-flick test animals were divided in three groups $(n=10$ animals/group) and rats were treated intraperitoneally with $10 \mathrm{mg} / \mathrm{kg}$ caffeic acid or rosmarinic acid. The control group animals received the same experimental handling as those of the test groups except that the drug treatment was replaced with appropriate volumes of the dosing saline.

2.3. Pleurisy Induction. Rats anaesthetized with ethyl ether, and injected intrapleurally with $0.1 \mathrm{~mL}$ of a $1 \mathrm{mg} / \mathrm{mL}$ solution of carrageenan, as described by Spector [27]. Four hours later, the animals were sacrificed with ethyl ether and the pleural cavities were exposed. The exudates were collected and the cavity was flushed with $2 \mathrm{~mL}$ of phosphated-buffered saline (PBS). The total leukocyte number in the pleural exudate was counted in a Neubauer chamber. Slides of the cellular exudate were also prepared and differential cell counting was performed. In this experiment leukocytes accumulation in the peripheral blood was also determined. Rats were first anaesthetised and blood samples were taken from the tail before and after 4 hours of the carrageenan injection for differential leukocyte counting.

2.4. Antinociception Recording. Nociception was assessed with a tail-flick apparatus (Insight EFF-300) [28]. Rats were wrapped in a towel and placed on the apparatus, the light source positioned below the tail was focused on a point $2-3 \mathrm{~cm}$ rostral to the tip of the tail. Deflection of the tail activated a photocell and automatically terminated the trial. Normal response latencies were usually between 2.5 and 3.0 seconds, and a 10 seconds cutoff was used to prevent tissue damage. Tail-flick latency represented the period of time from the beginning of the trial to the tail deflection. On day 1 , subjects were familiarized with the tail-flick apparatus. This was done because it has been observed that novelty itself can induce antinociception [29]. On day 2, animals were submitted to the tail-flick measurement.

2.5. Statistical Analysis. Data from pleurisy are expressed as mean \pm standard error (S.E.M.). Comparisons between counting before and after pleurisy induction were performed using paired Students $t$-test. ANOVA and Tukey test were used to compare the treatment groups. Latency to tail-flick (nonparametric data) are expressed as median (interquartil range) and were analyzed by a Mann-Whitney $U$-test (independent samples) or by Wilcoxon Matched-Pairs Test (related samples).

\section{Results}

3.1. Effects of Caffeic and Rosmarinic Acids on CarrageenanInduced Pleurisy. Total number of leukocytes showed a significant increase in both groups (treated and control) in Table 1. The leukocytes recruited to the peripheral circulation, which is primarily indicated by the increase in the number of neutrophils after the induction of inflammation.

The analysis of cells in the pleural exudates revealed a reduction of $66 \%$ of the number of leukocytes that migrated to the pleural cavity in the animals treated with $5 \mathrm{mg} / \mathrm{kg}$ caffeic acid, and of $92.9 \%$ for the animals treated with $10 \mathrm{mg} / \mathrm{kg}$ in comparison with the control group. These exudates showed a balanced distribution of polymorphonuclear $(\mathrm{PMN})$ and mononuclear (MN) cells, as shown in Table 2, differently from the control group, in which PMN cells were predominant.

The administration of 5 and $10 \mathrm{mg} / \mathrm{kg}$ produced marked increases in total leukocyte counts after inflammation induction. However, only the animals treated with $10 \mathrm{mg} / \mathrm{kg}$ showed a significantly greater number of neutrophils than the animals in the control group, both before and after the administration of carrageenan (Table 1), as well as a significant increase in the number of lymphocytes after 
TABLE 1: Effect of rosmarinic acid (RA) and caffeic acid (CA) on leukocytes of peripheral blood before and after inflammatory process induction.

\begin{tabular}{|c|c|c|c|c|c|c|}
\hline Treatment & $\begin{array}{c}\text { Total leukocyte } \\
\text { (before) }\end{array}$ & $\begin{array}{c}\text { Total leukocyte } \\
\text { (after) }\end{array}$ & $\begin{array}{c}\text { Neutrophils } \\
\text { (before) }\end{array}$ & $\begin{array}{c}\text { Neutrophils } \\
\text { (after) }\end{array}$ & $\begin{array}{c}\text { Lymphocytes } \\
\text { (before) }\end{array}$ & $\begin{array}{c}\text { Lymphocytes } \\
\text { (after) }\end{array}$ \\
\hline $\begin{array}{l}\text { Control } \\
n=7\end{array}$ & $7350 \pm 3127.9$ & $11175 \pm 1607.4^{*}$ & $1183.75 \pm 519.5$ & $4779.83 \pm 1664.9^{* *}$ & $5826.75 \pm 2512$ & $5401.3 \pm 917.73$ \\
\hline $\begin{array}{l}\mathrm{RA}(5 \mathrm{mg} / \mathrm{kg}) \\
n=7\end{array}$ & $7875 \pm 2332.76$ & $12850 \pm 2202.95^{* *}$ & $1743.25 \pm 833.16$ & $6013.6 \pm 1548.85^{* *}$ & $5818.75 \pm 1960$ & $6054.42 \pm 1816.62$ \\
\hline $\begin{array}{l}\mathrm{RA}(10 \mathrm{mg} / \mathrm{kg}) \\
n=7\end{array}$ & $8800 \pm 1945.5$ & $14808.33 \pm 1120.45^{* * \mathrm{~A}}$ & $2057.42 \pm 769.85^{\mathrm{B}}$ & $7007.17 \pm 994.97^{* * \mathrm{~B}}$ & $6274.42 \pm 2267.66$ & $7270.25 \pm 1297.25^{\mathrm{B}}$ \\
\hline $\begin{array}{l}\mathrm{CA}(5 \mathrm{mg} / \mathrm{kg}) \\
n=7\end{array}$ & $9100 \pm 1801.4$ & $14075 \pm 1553.57^{* * A}$ & $1530.56 \pm 1023.2$ & $6659.81 \pm 2044.2^{* *}$ & $6890.5 \pm 1582.5$ & $6307.63 \pm 1478$ \\
\hline $\begin{array}{l}\mathrm{CA}(10 \mathrm{mg} / \mathrm{kg}) \\
n=7\end{array}$ & $7625 \pm 1906.24$ & $12658.33 \pm 3598.95^{* * \mathrm{~A}}$ & $820.58 \pm 387.23$ & $4758.25 \pm 2337.54^{* *}$ & $6479.3 \pm 1746.42$ & $7387.58 \pm 1615.63$ \\
\hline
\end{tabular}

Mean \pm standard error (SEM). Students $t$-test: Compared with control group ${ }^{\mathrm{A}} P<.05,{ }^{\mathrm{B}} P<.01$. Compared between before and after inflammatory induction process ${ }^{*} P<.05,{ }^{* *} P<.01$.

pleurisy induction in comparison with the control group. The analysis of cells that migrated to the pleural exudate revealed a significant reduction in leukocyte recruitment in comparison with the control group, with inhibition of $78.2 \%$ and $80.7 \%$ for animals treated with 5 and $10 \mathrm{mg} / \mathrm{kg}$. No predominance of PMN or MN cells was found in the exudate (Table 2).

The comparison of effects of the treatment with rosmarinic acid or caffeic acid on the inhibition of leukocyte migration to the inflammation sites revealed a significant difference in the group of animals treated with $10 \mathrm{mg} / \mathrm{kg}$ caffeic acid in comparison with the other groups. There was a reduction of $79.2 \%$ in the number of total exudate cells in the group that received $5 \mathrm{mg} / \mathrm{kg}$ caffeic acid, and of $67.6 \%$ and $63.3 \%$ in the group treated with 5 and $10 \mathrm{mg} / \mathrm{kg}$ of rosmarinic acid.

3.2. Effects of Rosmarinic and Caffeic Acids on Tail-Flick. Figure 1 shows a significant difference in the group of animals treated with $10 \mathrm{mg} / \mathrm{kg}$ caffeic acid in comparison with the other groups. The analysis revelated a high latency to tail-flick characterizing a nociceptive response. There was no difference between control group and animals treated with rosmarinic.

\section{Discussion}

The intrapleural administration of carrageenan into the pleural space leads to pleurisy, an inflammatory process characterized by an immediate recruitment of polymorphonuclear cells (PMN). Carrageenan is a high-molecularweight sulphated polysaccharide, capable of inducing the release of mediators involved in vascular changes associated with acute inflammation [30]. The inflammation in the respiratory pathway induces histamine, thromboxane A2, leukotrienes, cytokines, and nitric oxide release [31].

Rosmarinic acid is a natural phenolic compound contained in many Lamiaceae herbs. The medicinal value of this substance has been well recognized, especially in regard to its antioxidant and anti-inflammatory process. Sabongi et al.

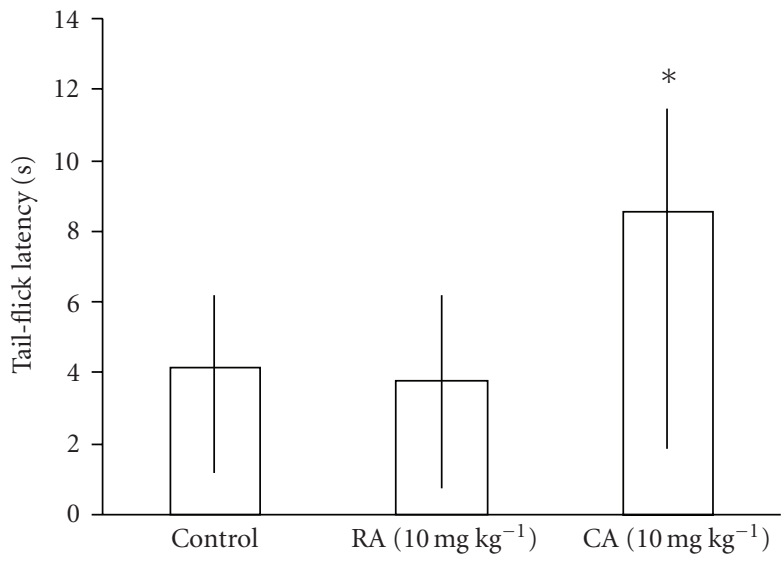

Figure 1: Effect of caffeic acid (CA) and rosmarinic acid (RA) on the tail-flick test in rats. Data expressed as median (interquartiles range) of the tail-flick latencies ( $n=10 \mathrm{animal} /$ group). MannWhitney $U$-test: ${ }^{*} P<.05$ compared with control group.

[20] observed that rosmarinic acid inhibited pathophysiological changes such as neutrophilic inflammation and edema in the lung, in mice treated with administration of rosmarinic acid ( $2 \mathrm{mg} /$ body for 3 days). These results suggested that rosmarinic acid inhibits diesel exhaust particles (DEPs) induced lung injury by the reduction of proinflammatory molecule expression. These effects were associated with the changes in proinflammatory cytokine and chemokine expression, which play a crucial role in the initiation and progression of the inflammatory response. Chemokines are a superfamily of small, structurally related chemotactic cytokines involved in leukocyte trafficking and activation [32].

Others studies on its anti-inflammatory activities led to its discovery as an inhibitor of complement [33]. It has been shown to inhibit both the classical and the alternative pathways of complement activation $[34,35]$ and complement dependent stimulation of prostacyclin synthesis [36]. In vivo it is known to inhibit cobra venom factorinduced paw edema $[33,34]$. 
TABLE 2: Migrated leucocytes into pleural exudate in rats treated with caffeic acid (CA) and rosmarinic acid (RA).

\begin{tabular}{lccc}
\hline Treatment & Total cells & $\begin{array}{c}\text { PMN } \\
\times 10^{6} \text { cells }\end{array}$ & MN \\
\hline $\begin{array}{l}\text { Control } \\
n=6\end{array}$ & $1.56 \pm 0.64$ & $1.12 \pm 0.57$ & $0.44 \pm 0.22$ \\
$\begin{array}{l}\mathrm{RA}\left(5 \mathrm{mg} \mathrm{kg}^{-1}\right) \\
n=6\end{array}$ & $0.34 \pm 0.35^{\mathrm{A}}$ & $0.18 \pm 0.14^{\mathrm{A}}$ & $0.16 \pm 0.13^{\mathrm{B}}$ \\
$\mathrm{RA}\left(10 \mathrm{mg} \mathrm{kg}^{-1}\right)$ & $0.30 \pm 0.15^{\mathrm{A}}$ & $0.18 \pm 0.10^{\mathrm{A}}$ & $0.12 \pm 0.08^{\mathrm{A}}$ \\
$n=6$ & $0.53 \pm 0.17^{\mathrm{A}}$ & $0.25 \pm 0.12^{\mathrm{A}}$ & $0.28 \pm 0.18$ \\
$\mathrm{CA}\left(5 \mathrm{mg} \mathrm{kg}^{-1}\right)$ & $0.11 \pm 0.008^{\mathrm{A} 1}$ & $0.005 \pm 0.003^{\mathrm{A} 1}$ & $0.006 \pm 0.003^{\mathrm{A} 1}$ \\
$n=8$ & & & \\
CA $\left(10 \mathrm{mg} \mathrm{kg}^{-1}\right)$ & & & \\
$n=6$
\end{tabular}

Values are Mean \pm S E M. PMN: polymorphonuclear cells. MN: mononuclear cells. Student's $t$-test: Compared with control group: ${ }^{\mathrm{A}} P<.05,{ }^{\mathrm{B}} P<.01$.

ANOVA/Tukey: Compared between groups: ${ }^{1} P<.05$.

Caffeic acid (3,4-dihydroxycinnamic acid) is one of the natural phenolic compounds widely distributed in plant materials such as vegetables, fruits, coffee, and tea [36]. This substance as an antioxidant can scavenge a number of reactive species, including 1,1-diphenyl-2-picryl-hydrazyl free radical (DPPH) $[25,26]$, peroxyl [23], and hydroxyl radicals [24] as well as superoxide anion, peroxynitrite, and mutagenic compounds such as nitrosamines [24, 26]. Caffeic acid also inhibits 5-lipoxygenase (5-LOX) activity [21], and inhibits protein kinase $\mathrm{C}(\mathrm{PKC})$, PKA and nuclear factor- $\kappa \mathrm{B}$ (NF- $\kappa \mathrm{B})$ activation induced by ceramides in U937 cells [22]. Others studies have been also reported to have antitumor activity [37, 38], anti-inflammatory properties [39], and anti-HIV replication activity [40].

In the present study, we confirmed the anti-inflammatory ability of caffeic and rosmarinic acids in animal model. Experimental evidences obtained in the present study indicated that caffeic acid and rosmarinic acid were able to reduce polymorphonuclear and mononuclear cells migration into pleural space, 4 hours after pleurisy induction by carrageenan. We also observed that animals treated with $10 \mathrm{mg} / \mathrm{kg}$ caffeic acid produced an analgesic effect 30 minutes after drug administration on tail-flick model. Our results are in agreement with those reported by Shin et al. 2004 [41] where animals treated with caffeic acid at some dose, significantly increased the latency of the jumping response, and the animals were not able to detect pain by hot plate test.

Other studies investigating the pharmacological profile of these compounds showed that rosmarinic acid may present an anxiolytic-like activity when used in low doses, without affecting the locomotion, exploration, and motivation [42]. In this work an intermediary doses were chosen based on the literature [42]. The fact that caffeic acid produced analgesic effect in the nociceptive model is indicative that it had both central and periferic antinociception and the mechanism of action could be partially related to lipoxygenase and/or cyclooxygenase of the arachidonic acid cascade and/or opioid receptors [43, 44]. Analgesic effect reflected in tail-flick tests is dependent on centrally action opioid-like analgesics
$[44,45]$. Taken together, our results obtained in the tail-flick model corroborated that caffeic acid had central analgesic activity, possibly by crossing the blood-brain barrier.

In our study, we observed the anti-inflammatory and antinociceptive effect was more pronounced in animals treated with caffeic acid as compared to those treated with rosmarinic acid. Germanò et al. [46] studied rats treated with nonhydrolyzed extract of Trichilia emetica Vahl and they were detected in plasma levels of caffeic acid at 15 and 30 minutes after, and they suggested its greater absorption in vivo by intestinal cells. Baba et al. [47] studying rosmarinic acid bioavailability in orally treated rats, verified maximal serum concentration of this substance 1 hour after administration. Rosmarinic acid was immediately metabolized, and one of its metabolites is caffeic acid. Therefore, we suggest that the anti-inflammatory effect observed in rats treated with rosmarinic acid, is probably due to its breakdown products, such as caffeic acid, as the highest inhibition of leukocyte migration to the primary site of inflammation was obtained with caffeic acid at $10 \mathrm{mg} / \mathrm{kg}$.

In conclusion, the results of the present study provide further evidences of the anti-inflammatory and analgesic properties of these phenolics compounds, which therefore have potential applications in pain and inflammatory diseases, with caffeic acid presenting the most potent antiinflammatory and antinociceptive effects in these animal models. However, further studies are needed to establish the mechanism of the observed actions.

\section{Acknowledgment}

This work was supported by Feevale/aspeur and FAPERGS.

\section{References}

[1] R. Sobota, M. Szwed, A. Kasza, M. Bugno, and T. Kordula, "Parthenolide inhibits activation of signal transducers and activators of transcription (STATs) induced by cytokines of the IL-6 family," Biochemical and Biophysical Research Communications, vol. 267, no. 1, pp. 329-333, 2000. 
[2] A. Tomlinson, I. Appleton, A. R. Moore et al., "Cyclooxygenase and nitric oxide synthase isoforms in rat carrageenin-induced pleurisy," British Journal of Pharmacology, vol. 113, no. 3, pp. 693-698, 1994.

[3] S. Cuzzocrea, B. Pisano, L. Dugo et al., "Rosiglitazone, a ligand of the peroxisome proliferator-activated receptor- $\gamma^{3}$, reduces acute inflammation," European Journal of Pharmacology, vol. 483, no. 1, pp. 79-93, 2004.

[4] B. Halliwell, J. R. Hoult, and D. R. Blake, "Oxidants, inflammation, and anti-inflammatory drugs," FASEB Journal, vol. 2, no. 13, pp. 2867-2873, 1988.

[5] W. A. Verri, T. M. Cunha, C. A. Parada, S. Poole, F. Q. Cunha, and S. H. Ferreira, "Hypernociceptive role of cytokines and chemokines: targets for analgesic drug development?" Pharmacology and Therapeutics, vol. 112, no. 1, pp. 116-138, 2006.

[6] D. Julius and A. I. Basbaum, "Molecular mechanisms of nociception," Nature, vol. 413, no. 6852, pp. 203-210, 2001.

[7] R. R. Ji and G. Strichartz, "Cell signaling and the genesis of neuropathic pain," Science's STKE, vol. 2004, no. 252, article reE14, 2004.

[8] C. R. Ganellin, "General approaches to discovering new drugs: an historical perspective," in Medicinal Chemistry, Academic Press, London, UK, 1993.

[9] M. Petersen and M. S. J. Simmonds, "Rosmarinic acid," Phytochemistry, vol. 62, no. 2, pp. 121-125, 2003.

[10] M. R. Al-Sereiti, K. M. Abu-Amer, and P. Sen, "Pharmacology of rosemary (Rosmarinus officinalis Linn.) and its therapeutic potentials," Indian Journal of Experimental Biology, vol. 37, no. 2, pp. 124-130, 1999.

[11] A. Sahu, N. Rawal, and M. K. Pangburn, "Inhibition of complement by covalent attachment of rosmarinic acid to activated C3b," Biochemical Pharmacology, vol. 57, no. 12, pp. 1439-1446, 1999.

[12] M. A. Kelm, M. G. Nair, G. M. Strasburg, and D. L. DeWitt, "Antioxidant and cyclooxygenase inhibitory phenolic compounds from Ocimum sanctum Linn," Phytomedicine, vol. 7, no. 1, pp. 7-13, 2000.

[13] W. Zheng and S. Y. Wang, "Antioxidant activity and phenolic compounds in selected herbs," Journal of Agricultural and Food Chemistry, vol. 49, no. 11, pp. 5165-5170, 2001.

[14] M. A. Kang, S. Y. Yun, and J. Won, "Rosmarinic acid inhibits $\mathrm{Ca}$-dependent pathways of T-cell antigen receptor-mediated signaling by inhibiting the PLC- $\gamma 1$ and Itk activity," Blood, vol. 101, no. 9, pp. 3534-3542, 2003.

[15] W. Bors, C. Michel, K. Stettmaier, Y. Lu, and L. Y. Foo, "Antioxidant mechanisms of polyphenolic caffeic acid oligomers, constituents of Salvia officinalis," Biological Research, vol. 37, no. 2, pp. 301-311, 2004.

[16] L. P. Gao, H. L. Wei, H. S. Zhao, S. Y. Xiao, and R. L. Zheng, "Antiapoptotic and antioxidant effects of rosmarinic acid in astrocytes," Pharmazie, vol. 60, no. 1, pp. 62-65, 2005.

[17] M. J. Parnham and K. Kesselring, "Rosmarinic acid," Drugs of the Future, vol. 10, no. 9, pp. 756-757, 1985.

[18] W. Krol, S. Scheller, Z. Czuba et al., "Inhibition of neutrophils' chemiluminescence by ethanol extract of propolis (EEP) and its phenolic components," Journal of Ethnopharmacology, vol. 55, no. 1, pp. 19-25, 1996.

[19] O. K. Mirzoeva and P. C. Calder, "The effect of propolis and its components on eicosanoid production during the inflammatory response," Prostaglandins Leukotrienes and Essential Fatty Acids, vol. 55, no. 6, pp. 441-449, 1996.
[20] C. Sanbongi, H. Takano, N. Osakabe et al., "Rosmarinic acid inhibits lung injury induced by diesel exhaust particles," Free Radical Biology and Medicine, vol. 34, no. 8, pp. 1060-1069, 2003.

[21] K. Yasuko, N. Tomohiro, M. Sei-Itsu, L. Ai-Na, F. Yasuo, and T. Takashi, "Caffeic acid is a selective inhibitor for leukotriene biosynthesis," Biochimica et Biophysica Acta, vol. 792, no. 1, pp. 92-97, 1984.

[22] M. Nardini, F. Leonardi, C. Scaccini, and F. Virgili, "Modulation of ceramide-induced NF- $\kappa \mathrm{B}$ binding activity and apoptotic response by caffeic acid in U937 cells: comparison with other antioxidants," Free Radical Biology and Medicine, vol. 30, no. 7, pp. 722-733, 2001.

[23] C. Castelluccio, G. Paganga, N. Melikian et al., "Antioxidant potential of intermediates in phenylpropanoid metabolism in higher plants," FEBS Letters, vol. 368, no. 1, pp. 188-192, 1995.

[24] Y. Kono, K. Kobayashi, S. Tagawa et al., "Antioxidant activity of polyphenolics in diets. Rate constants of reactions of chlorogenic acid and caffeic acid with reactive species of oxygen and nitrogen," Biochimica et Biophysica Acta, vol. 1335, no. 3, pp. 335-342, 1997.

[25] H. Kikuzaki, M. Hisamoto, K. Hirose, K. Akiyama, and H. Taniguchi, "Antioxidant properties of ferulic acid and its related compounds," Journal of Agricultural and Food Chemistry, vol. 50, no. 7, pp. 2161-2168, 2002.

[26] I. Gülçin, "Antioxidant activity of caffeic acid (3,4-dihydroxycinnamic acid)," Toxicology, vol. 217, no. 2-3, pp. 213-220, 2006.

[27] W. G. Spector, "The mediation of altered capillary permeability in acute inflammation," Journal of Pathology \& Bacteriology, vol. 72, pp. 367-380, 1956.

[28] F. E. D’Amour and D. L. Smith, “A method for determining loss of pain sensation," Journal of Pharmacology and Experimental Therapeutics, vol. 72, pp. 74-79, 1941.

[29] C. A. Netto, B. Siegfried, and I. Izquierdo, "Analgesia induced by exposure to a novel environment in rats: effect of concurrent and post-training stressful stimulation," Behavioral and Neural Biology, vol. 48, no. 2, pp. 304-309, 1987.

[30] E. Corsini, R. Di Paola, B. Viviani et al., "Increased carrageenan-induced acute lung inflammation in old rats," Immunology, vol. 115, no. 2, pp. 253-261, 2005.

[31] S. Y. Eum, K. Maghni, Q. Hamid et al., "Inhibition of allergic airways inflammation and airway hyperresponsiveness in mice by dexamethasone: role of eosinophils, IL-5, eotaxin, and IL13," Journal of Allergy and Clinical Immunology, vol. 111, no. 5, pp. 1049-1061, 2003.

[32] T. S. Olson and K. Ley, "Chemokines and chemokine receptors in leukocyte trafficking," American Journal of Physiology, vol. 283, no. 1, pp. R7-R28, 2002.

[33] S. Leyck, E. Etschenberg, U. Hadding, and J. Winkelmann, "A new model of acute inflammation: Cobra venom factor induced paw oedema," Agents and Actions, vol. 13, no. 5-6, pp. 437-438, 1983.

[34] W. Englberger, U. Hadding, E. Etschenberg et al., "Rosmarinic acid: a new inhibitor of complement C3-convertase with antiinflammatory activity," International Journal of Immunopharmacology, vol. 10, no. 6, pp. 729-737, 1988.

[35] P. W. Peake, B. A. Pussell, P. Martyn, V. Timmermans, and J. A. Charlesworth, "The inhibitory effect of rosmarinic acid on complement involves the C5 convertase," International Journal of Immunopharmacology, vol. 13, no. 7, pp. 853-857, 1991. 
[36] M. Rampart, J. R. Beetens, and H. Bult, "Complementdependent stimulation of prostacyclin biosynthesis: inhibition by rosmarinic acid," Biochemical Pharmacology, vol. 35, no. 8, pp. 1397-1400, 1986.

[37] T. Tanaka, T. Kojima, T. Kawamori et al., "Inhibition of 4-nitroquinoline-1-oxide-induced rat tongue carcinogenesis by the naturally occurring plant phenolics caffeic, ellagic, chlorogenic and ferulic acids," Carcinogenesis, vol. 14, no. 7, pp. 1321-1325, 1993.

[38] K. Frenkel, H. Wei, R. Bhimani et al., "Inhibition of tumor promoter-mediated processes in mouse skin and bovine lens by caffeic acid phenethyl ester," Cancer Research, vol. 53, no. 6, pp. 1255-1261, 1993.

[39] P. Michaluart, J. L. Masferrer, A. M. Carothers et al., "Inhibitory effects of caffeic acid phenethyl ester on the activity and expression of cyclooxygenase- 2 in human oral epithelial cells and in a rat model of inflammation," Cancer Research, vol. 59, no. 10, pp. 2347-2352, 1999.

[40] M. R. Fesen, K. W. Kohn, F. Leteurtre, and Y. Pommier, "Inhibitors of human immunodeficiency virus integrase," Proceedings of the National Academy of Sciences of the United States of America, vol. 90, no. 6, pp. 2399-2403, 1993.

[41] K. M. Shin, I. T. Kim, Y. M. Park et al., "Anti-inflammatory effect of caffeic acid methyl ester and its mode of action through the inhibition of prostaglandin E, nitric oxide and tumor necrosis factor- $\alpha$ production," Biochemical Pharmacology, vol. 68, no. 12, pp. 2327-2336, 2004.

[42] P. Pereira, D. Tysca, P. Oliveira, L. F. D. S. Brum, J. N. Picada, and P. Ardenghi, "Neurobehavioral and genotoxic aspects of rosmarinic acid," Pharmacological Research, vol. 52, no. 3, pp. 199-203, 2005.

[43] R. Deraedt, S. Jouquey, F. Delevallee, and M. Flahaut, "Release of prostaglandins $\mathrm{E}$ and $\mathrm{F}$ in an algogenic reaction and its inhibition," European Journal of Pharmacology, vol. 61, no. 1, pp. 17-24, 1980.

[44] D. Le Bars, M. Gozariu, and S. W. Cadden, "Animal models of nociception," Pharmacological Reviews, vol. 53, no. 4, pp. 597652, 2001.

[45] J. Connor, E. Makonnen, and A. Rostom, "Comparison of analgesic effects of khat (Catha edulis Forsk) extract, Damphetamine and ibuprofen in mice," Journal of Pharmacy and Pharmacology, vol. 52, no. 1, pp. 107-110, 2000.

[46] M. P. Germanò, V. D’Angelo, T. Biasini, R. Sanogo, R. De Pasquale, and S. Catania, "Evaluation of the antioxidant properties and bioavailability of free and bound phenolic acids from Trichilia emetica Vahl," Journal of Ethnopharmacology, vol. 105, no. 3, pp. 368-373, 2006.

[47] S. Baba, N. Osakabe, M. Natsume, and J. Terao, "Orally administered rosmarinic acid is present as the conjugated and/or methylated forms in plasma, and is degraded and metabolized to conjugated forms of caffeic acid, ferulic acid and m-coumaric acid," Life Sciences, vol. 75, no. 2, pp. 165178, 2004. 

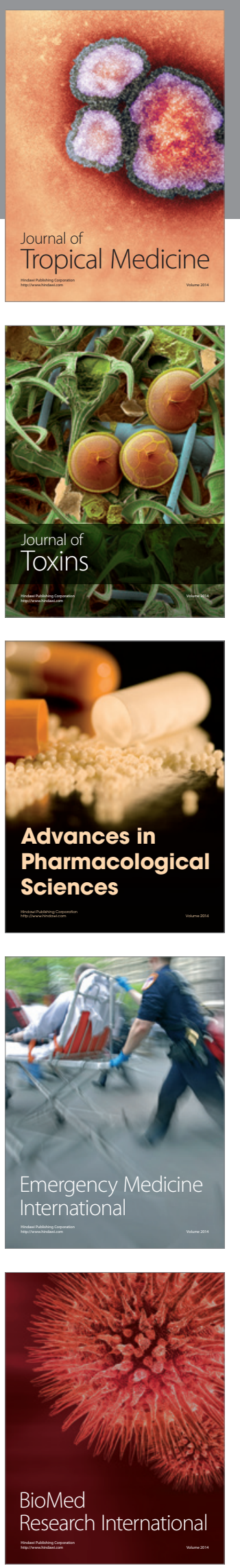
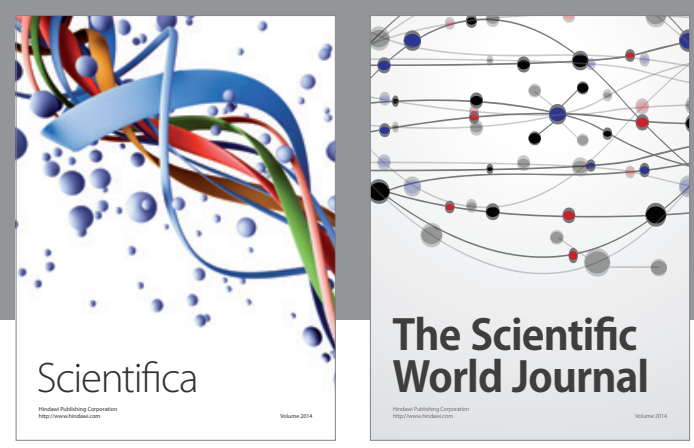

The Scientific World Journal
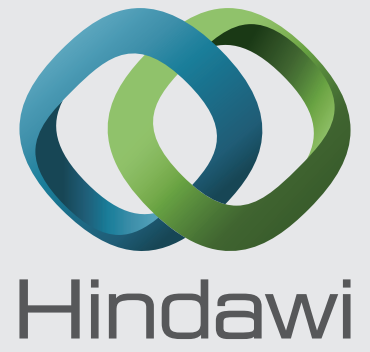

Submit your manuscripts at

http://www.hindawi.com
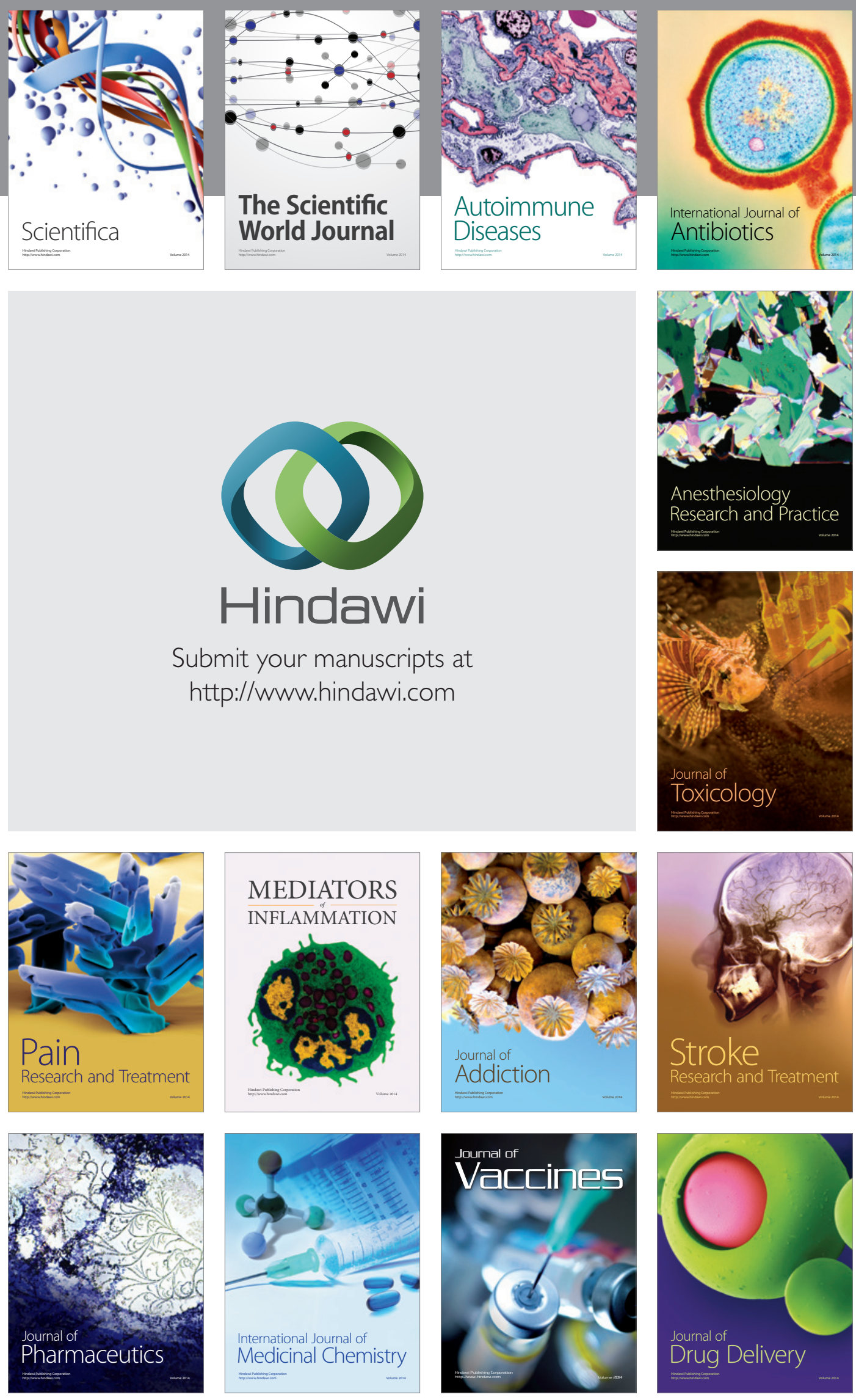